\title{
Eflorescência salina na igreja de Santo Alexandre, Belém - PA
}

The salt efflorescence in the Church of Santo Alexandre, Belém - PA

\author{
Alexandre Máximo Silva Loureiro \\ Rômulo Simões Angélica \\ Thais Alessandra Bastos Caminha Sanjad \\ Mário Mendonça de Oliveira \\ Marcondes Lima da Costa
}

\section{Resumo

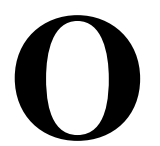

s monumentos históricos de Belém, PA, têm alvenarias estruturais constituídas de pedras e tijolos maciços assentados com argamassa de cal e podem apresentar diversas patologias, entre as quais se destacam a eflorescência salina e a ação da umidade. Alguns autores explicam que esses dois agentes ocasionam destacamento de camadas, pulverização de argamassa, surgimento de fissuras e aparência esbranquiçada. A pesquisa teve como principal objetivo identificar o processo de degradação atuante na alvenaria do transepto direito da Igreja de Santo Alexandre por meio da aplicação de técnicas instrumentais analíticas. Foram realizadas análises laboratoriais com o intuito de entender as condicionantes favoráveis ao processo de eflorescência salina, os danos provocados aos materiais e os tipos de sais mais atuantes. Primeiramente foi realizado o mapeamento da alvenaria e o mapeamento de danos, verificando a situação atual e as áreas mais degradadas. Posteriormente, foi realizada a caracterização física por meio de análise granulométrica, análise de traço e análise do teor de umidade da alvenaria, a caracterização química - teste qualitativo e quantitativo de sais - e a caracterização mineralógica por difração de

Alexandre Máximo Silva Loureiro Universidade Federal do Pará Belém - PA - Brasil

Rômulo Simões Angélica Universidade Federal do Pará Belém - PA - Brasil

Thais Alessandra Bastos Caminha Sanjad Universidade Federal do Pará Belém - PA - Brasil

Mário Mendonça de Oliveira

Universidade Federal da Bahia Salvador - BA - Brasil

Marcondes Lima da Costa Universidade Federal do Pará Belém - PA - Brasil

Recebido em 07/10/14

Aceito em 02/05/15 raios X. Verificou-se que as técnicas aplicadas se mostraram eficientes e auxiliaram no diagnóstico correto, norteando quais intervenções devem ser utilizadas para amenizar a problemática.

Palavras-chaves: Alvenaria mista. Eflorescência salina. Mapa de danos.

\section{Abstract}

The structural masonry of the historical monuments of the city of Belém, Brazil, is made of stones and solid bricks fixed with lime mortar, which is affected by different pathologies, including salt efflorescence and moisture action. Some authors explain that these two agents cause layer detachment, mortar pulverization, cracks and a whitened appearance. This aim of this study was to identify the degradation process affecting the masonry of the right transept of the Church of Santo Alexandre, using instrumental analytical techniques. Laboratory analyses were used in order to understand the saline efflorescence process, the material damage it causes and the main kinds of salts. The first step in the study was to map out the masonry and the damage, showing the current situation and the most damaged areas. That was followed by a physical characterisation through an analysis of mortar particle sizes and proportions, analysis of masonry moisture contents, chemical characterisation - qualitative and quantitative chemical analysis of soluble salts, and mineralogical characterisation by $X$-ray diffraction. The techniques applied were effective and contributed to the achievement of a correct diagnosis, guiding the type of interventions required to solve the problem.

Keywords: Mixed masonry. Salt efflorescence. Damage map. 


\section{Introdução}

A cidade de Belém, capital do Estado do Pará, localizada na Região Norte do Brasil, foi fundada em 12 de janeiro de 1616. Seu núcleo inicial correspondia à área onde hoje se situam o Forte do Castelo, a Casa das Onze Janelas, a Catedral da Sé e a Igreja de Santo Alexandre, todas remanescentes do Período Colonial.

A Igreja de Santo Alexandre (Figura 1) é um dos edifícios mais antigos desse elenco de monumentos, e sua importância reside no fato de ser um exemplar da arquitetura barroca, construída pelos jesuítas no século XVII. A Igreja passou por uma grande reforma interna no início do século XVIII. Apesar de ter permanecido fechada por cerca de 50 anos, a edificação conseguiu manter os principais traços característicos de sua arquitetura e de seus elementos construtivos. Com nave única, transepto e oito capelas laterais, a igreja tem uma sacristia com o mesmo comprimento da capelamor, localizada no braço direito da nave. Sua decoração, composta de peças produzidas por jesuítas e índios ou vindas de outras regiões do país, caracteriza-se como expressão de arte barroca de forte acento tropical (PARÁ, 2005).

Após vários anos sem uso, a Igreja passou por intervenção restaurativa em 1998, que teve por objetivo manter a leitura dos diversos períodos das edificações, sem a omissão de identificar as adaptações que foram necessárias à nova destinação dos espaços (PARÁ, 2005). Entre as mudanças que ocorreram com a intervenção restaurativa do final do século $\mathrm{XX}$, a edificação foi climatizada e foram removidos os rebocos de duas alvenarias (do transepto direito e da nave central).

A Igreja, assim como as demais edificações dela contemporâneas, foi erguida com a utilização de materiais naturais do próprio local e/ou advindos do Reino de Portugal. Suas paredes são de alvenaria mista, constituídas de tijolos maciços e pedras assentados com argamassa de cal. Em sua maioria, são alvenarias estruturais, ou seja, além de possuírem função de vedação, suportam as cargas da construção por toda a sua extensão.

O principal material da alvenaria era da região e corresponde a um arenito ferruginizado, vulgarmente conhecido como "pedra-jacaré", bastante utilizado tanto em alvenarias estruturais quanto na construção de alicerces das edificações antigas de toda a Amazônia. Essas pedras, possivelmente, eram provenientes de pedreiras situadas ao longo do rio Guamá, que banha a cidade. Juntamente com tijolos maciços, eram assentadas com argamassa de cal, areia e barro, sendo essa mistura também aplicada para rebocar as alvenarias.

A cal presente nas argamassas era obtida por meio da calcinação de conchas, coletadas nos chamados bancos de conchas, que se encontravam no litoral e no interior do continente. No largo da Sé foram construídos fornos de cal, não havendo, entretanto, indicação do resultado de seu aproveitamento, muito embora tivesse sido amplo, dado o número de casas que se levantaram nos bairros da Cidade e da Campina, com suas paredes feitas de cal e pedra, sólidas e bem construídas (CRUZ, 1898).

Figura 1 - Igreja de Santo Alexandre

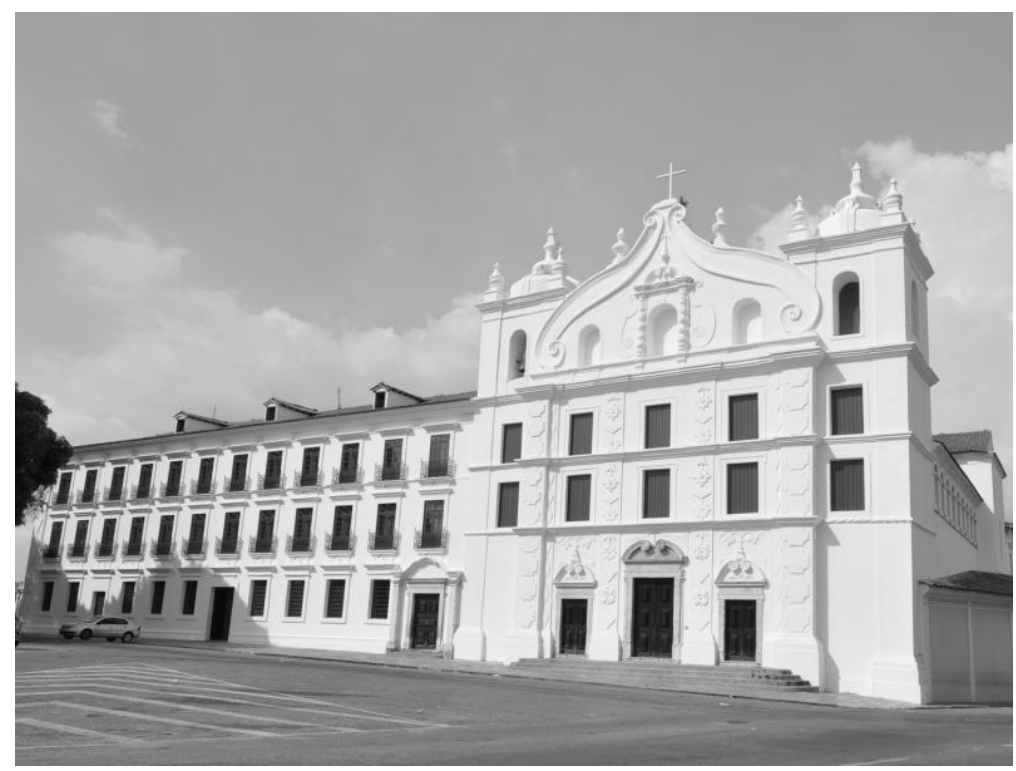

72 Loureiro, A. M. S.; Angélica, R. S.; Sanjad, T. A. B. C.; Oliveira, M. M. de; Costa, M. L. 
Além dos componentes da própria argamassa antiga, sua composição pode envolver ainda materiais adicionados propositalmente, como os aditivos orgânicos, ou mesmo vestígios do ambiente no qual a Igreja estava inserida, como sais e restos de raízes, folhas e insetos.

Contaminantes provenientes da própria matériaprima utilizada nas argamassas, como os sais, por exemplo, podem causar sérios danos nas estruturas antigas por meio do processo de eflorescência, que pode acontecer mesmo sem a presença de água nos muros, mas por higroscopicidade dos ditos sais, entre os quais se destaca o cloreto de sódio. Entretanto, outros sais, de diversas origens, ocasionam eflorescências, como os nitratos, provenientes de matéria orgânica em decomposição, e os sulfatos, provenientes da utilização de materiais como cimento e gesso. No caso de Santo Alexandre, após a recente intervenção restaurativa, e principalmente na parede em que foi removido o reboco, observou-se a rápida precipitação de sais tanto na superfície como nos poros dessas alvenarias. Diante do exposto, estabeleceu-se como objetivo desta pesquisa identificar o processo de degradação atuante na alvenaria com o apoio de técnicas instrumentais analíticas para obter subsídios para a conservação e a restauração das parcelas danificadas.

\section{Materiais e métodos}

\section{Materiais}

Para este estudo foi selecionada a alvenaria localizada no transepto direito da Igreja de Santo Alexandre (Figura 2), pois visualmente se trata da alvenaria mais degradada pela precipitação de sais. Desta alvenaria foram coletadas amostras de argamassa de assentamento e produtos de alteração, identificados no registro gráfico realizado previamente à coleta.

\section{Métodos}

\section{Mapeamento da alvenaria}

O registro gráfico e o mapeamento de danos foram feitos a partir da vetorização de imagens retificadas (ortofotos). Nesses mapeamentos foram identificados as diferentes zonas e os produtos de alteração, além de se registrarem os materiais constituintes da alvenaria. Esse levantamento levou em consideração a localização dos materiais presentes na alvenaria.

\section{Amostragem}

Foram estabelecidos nove pontos de coleta de amostras, três em cada extremidade e outros três no centro da alvenaria selecionada, recebendo nomenclatura de acordo com sua localização (Figura 3).

Figura 2 - Localização em planta da alvenaria estudada

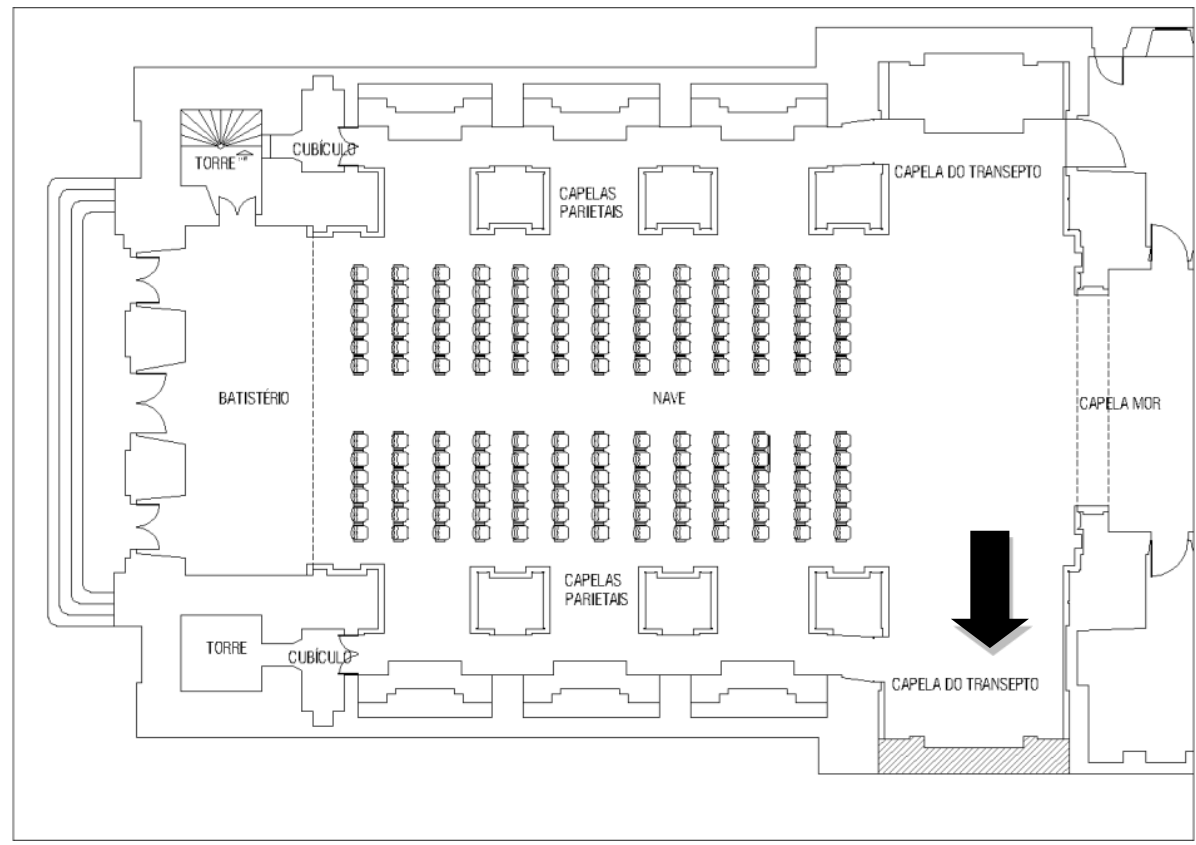


Figura 3 - Localização dos pontos de coleta e suas respectivas nomenclaturas

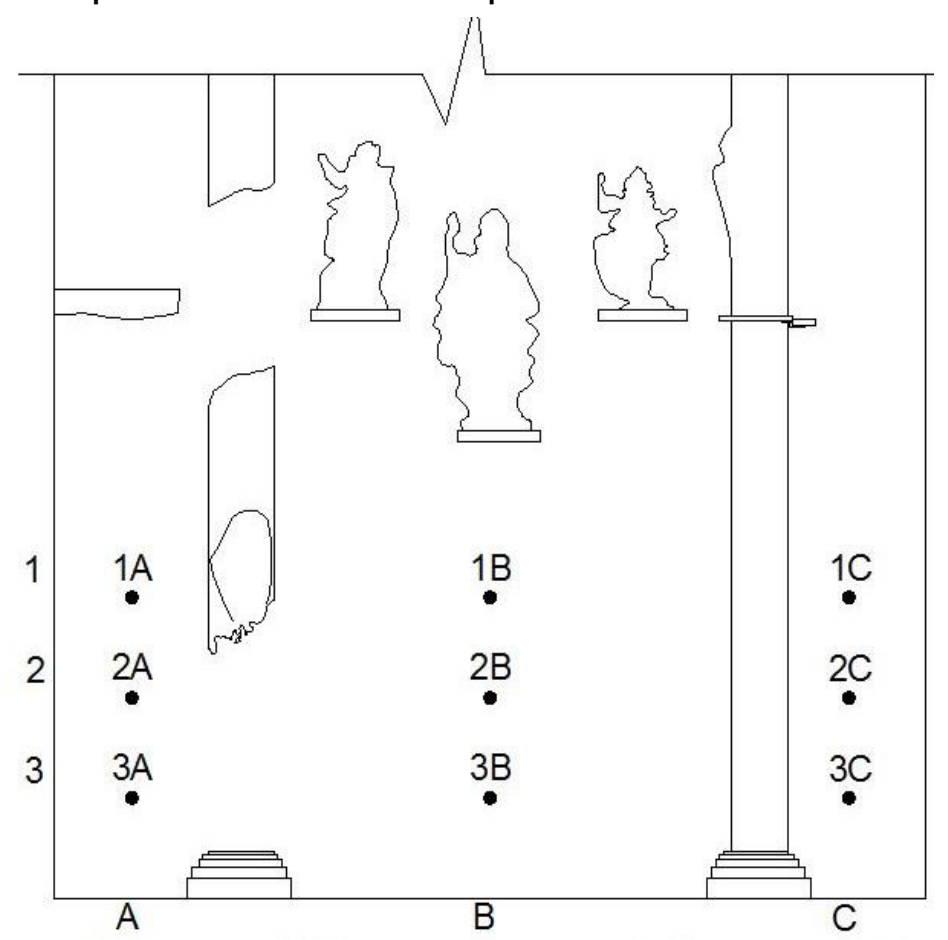

As amostras foram coletadas com o auxílio de perfuratriz portátil de baixa rotação da marca Eccofer e de uma broca diamantada de $10 \mathrm{~mm}$ de diâmetro, o que possibilitou análise não somente superficial, mas também de porções mais profundas da alvenaria. A perfuratriz portátil utilizada foi de baixa rotação para evitar a perda de umidade do material coletado por conta do aquecimento da broca; e a broca do tipo diamantada para evitar a contaminação das amostras com o material delas.

\section{Procedimentos laboratoriais}

Amostras de argamassa coletadas foram submetidas a análises de caracterização física, química e mineralógica. As análises mineralógicas por difração de raios X (DRX) e a análise do traço mais provável foram feitas centradas apenas na amostra 3B.

A umidade da alvenaria foi determinada por meio da pesagem das amostras coletadas em balança analítica antes e após secagem em estufa por $24 \mathrm{~h}$ a $75{ }^{\circ} \mathrm{C}$. Esse ensaio seguiu as recomendações do Laboratório Nacional de Engenharia Civil de Portugal (LNEC) (HENRIQUES, 1994).

$\mathrm{O}$ ensaio para a determinação do traço mais provável foi feito por meio de ataque com ácido clorídrico diluído em água destilada (proporção 1:4), aplicado na amostra, para que o ligante fosse dissolvido e dessa forma se pudesse chegar às proporções dos componentes da argamassa de cal analisada, ou seja, o ligante $\left[\mathrm{Ca}(\mathrm{OH})_{2}\right.$ ou $\left.\mathrm{Mg}(\mathrm{OH})_{2}\right]$ transformado em carbonato, os agregados finos (argila e/ou silte) e o agregado grosso (areia).

Após o ensaio de traço, os finos e os grossos da mesma amostra, obtidos após a desagregação por ataque ácido, foram utilizados para análise granulométrica por difração a laser. Com esses dados foi possível quantificar a frequência dos grãos argila $(0,01$ a $2 \mathrm{~d}[\mu \mathrm{m}])$, silte $(2$ a $50 \mathrm{~d}[\mu \mathrm{m}])$ ou areia $(50 \mathrm{a} 1.000 \mathrm{~d}[\mu \mathrm{m}])$. Essas análises foram realizadas com auxílio do equipamento Analyssete 22 - Wet Dispersion Unit, da marca Fritsch.

Para a análise mineralógica, empregaram-se o método do pó e o DRX, modelo X'PERT PRO $M P D$ (PW 3040/60), da PANalytical, com goniômetro PW3050/60 $(\theta / \theta)$, tubo de raios $\mathrm{X}$ cerâmico e anodo de $\mathrm{Cu}(\mathrm{K} \alpha 1=1,540598 \AA$ ), modelo PW3373/00, com foco fino $(2.200 \mathrm{~W} / 60$ $\mathrm{kV}$ ), e filtro $\mathrm{K} \beta$ de níquel. $\mathrm{O}$ detector utilizado é do tipo RTMS, X'Celerator. A interpretação dos difratogramas foi feita com o software High Score Plus, também da PANalytical.

Para o teste qualitativo de sais foram utilizados compostos químicos, de modo que as diferentes reações com as amostras coletadas permitissem a avaliação qualitativa da existência de cada tipo de sal:

(a) para a identificação de nitratos, utilizaram-se três gotas do reativo: $1 \%$ de difenilamina em $\mathrm{H}_{2} \mathrm{SO}_{4}$; 
(b) para a identificação de cloretos, utilizaram-se três gotas da solução da solução: $1 \%$ de $\mathrm{AgNO}_{3}$ em água deionizada; e

(c) para a identificação de sulfatos, utilizaram-se três gotas da solução: $5 \%$ de $\mathrm{BaCl}_{2} \mathrm{em} \mathrm{H}_{2} \mathrm{O}$ deionizada. Esses ensaios seguem as recomendações do LNEC (HENRIQUES, 1994).

Para a análise quantitativa de cloretos foram utilizados os seguintes reagentes:

(a) cloreto de sódio $100 \mathrm{mEq} / \mathrm{L}$ (100 mmol/L);

(b) nitrato de mercúrio $1,1 \mathrm{mmol} / \mathrm{L}$ e ácido nítrico $0,9 \mathrm{mmol} / \mathrm{L}$; e

(c) tiocianato de mercúrio $2 \mathrm{mmol} / \mathrm{L}$, nitrato férrico $17 \mathrm{mmol} / \mathrm{L}$ e ácido nítrico $30 \mathrm{mmol} / \mathrm{L}$.

Os íons cloreto presentes na amostra reagem com o tiocianato de mercúrio formando cloreto mercúrico e íons tiocianato. Os íons tiocianato reagem com os íons férricos formando tiocianato férrico de cor amarela, e a intensidade da cor é diretamente proporcional à concentração de cloretos na amostra analisada. A leitura foi feita em Espectrofotômetro SpectroDirect, da Lovibond, para análise de águas do mar.

Os ensaios para determinação do traço mais provável e a determinação do teor de umidade foram realizados no Laboratório de Conservação, Restauração e Reabilitação (LACORE) da Universidade Federal do Pará (UFPA).

No Instituto de Geociências da Universidade Federal do Pará foram efetivadas as seguintes análises, em seus respectivos laboratórios:

(a) análises de DRX, realizadas no Laboratório de Caracterização Mineral; e

(b) análise granulométrica, realizada no Laboratório de Mineralogia e Geoquímica Aplicada (LaMIGA).

Os ensaios para determinação qualitativa de sais solúveis e determinação quantitativa de cloretos foram realizados no Núcleo de Tecnologia da Preservação e da Restauração (NTPR) da Universidade Federal da Bahia.

\section{Resultados}

\section{Características da alvenaria}

Trata-se de alvenaria do tipo misto, constituída de blocos de arenito ferruginizado (popularmente conhecido por "pedra-jacaré") e tijolos cerâmicos maciços, assentados com argamassa de cal
(Figuras 4 e 5). Em alguns pontos da alvenaria podem ser vistos resquícios de conchas, material utilizado como matéria-prima para a obtenção da cal.

O mapeamento limitou-se até a altura de 3,50 m por se tratar da região dada como limite da degradação, pois acima deste os constituintes da alvenaria encontram-se mais bem conservados e com pouca influência das eflorescências salinas. Em outras palavras, quanto maior a altura, menor a degradação dos constituintes.

Os tijolos encontram-se principalmente nas áreas da base das pilastras, nos arcos de descarga e na região central da alvenaria, enquanto os blocos de arenito são em maior número em relação aos tijolos e estão distribuídos por toda a estrutura. Atualmente, sua espessura é de aproximadamente $1 \mathrm{~m}$. Conforme já descrito, anteriormente a Igreja era revestida com argamassa de cal, areia e barro, tendo sido esse reboco removido no projeto de intervenção de 1998.

De modo geral, o mapeamento de danos indicou existência de zonas com diferentes níveis de alteração com precipitação de sais, eflorescência (Figura 6). A área mais degradada corresponde à parte inferior da alvenaria.

Os seguintes tipos de alterações foram reconhecidos: fissuras, manchas de umidade $\mathrm{e}$ dissolução dos materiais. A dissolução dos materiais se manifesta de duas diferentes formas:

(a) a argamassa apresenta maior grau de dissolução, com desagregação de seus constituintes, que se tornam pulverulentos; e

(b) os blocos de arenito apresentam cavidades em sua superfície, enquanto os tijolos se apresentam mais bem conservados.

Na Figura 6, apesar de ter sido representada uma mudança abrupta de áreas, há, na verdade, uma mudança gradativa da região mais degradada para a região menos degradada.

\section{Argamassa}

As análises indicaram como traço mais provável a relação 1:0,87:3,98 (cal:barro:areia). Essa proporção entre os materiais constituintes mostra que se trata de argamassa forte e com pouca quantidade de finos (silte e argila), sendo a relação, em peso, aglomerante:agregado de 1:4. 
Figura 4 - Imagem retificada do transepto direito da Igreja de Santo Alexandre

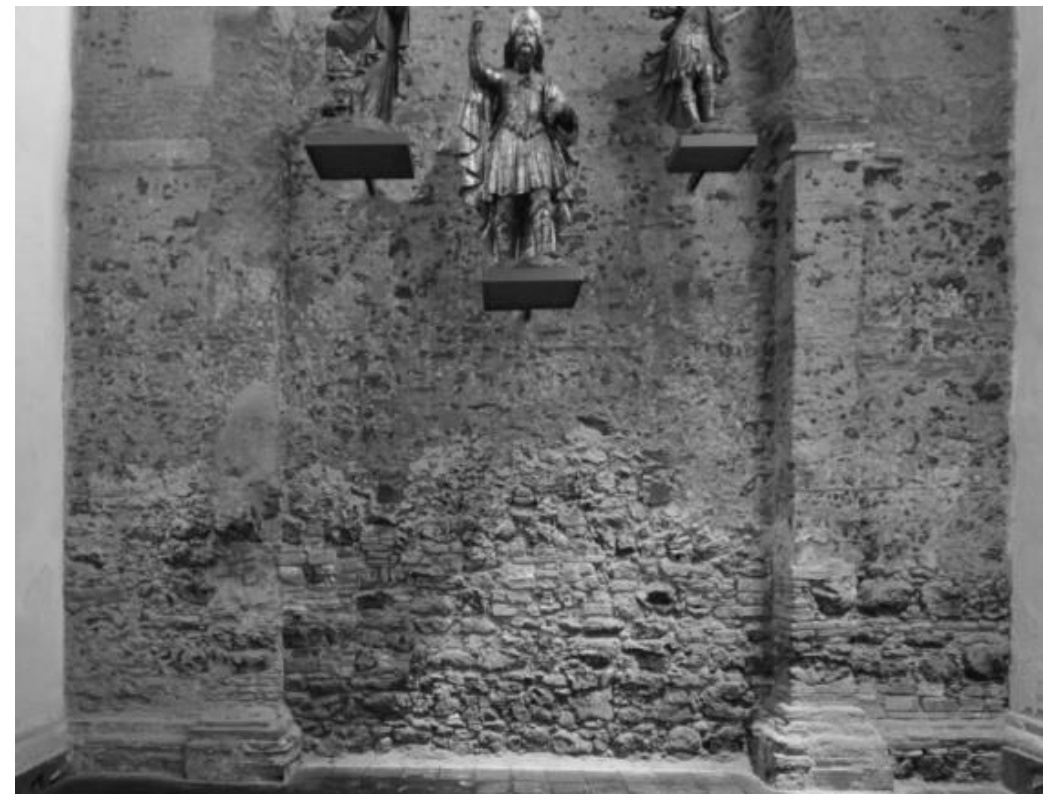

Figura 5 - Mapeamento da alvenaria a partir da foto retificada - os elementos constituintes são os blocos de arenito ferruginizado e os tijolos cerâmicos maciços dispersos na argamassa

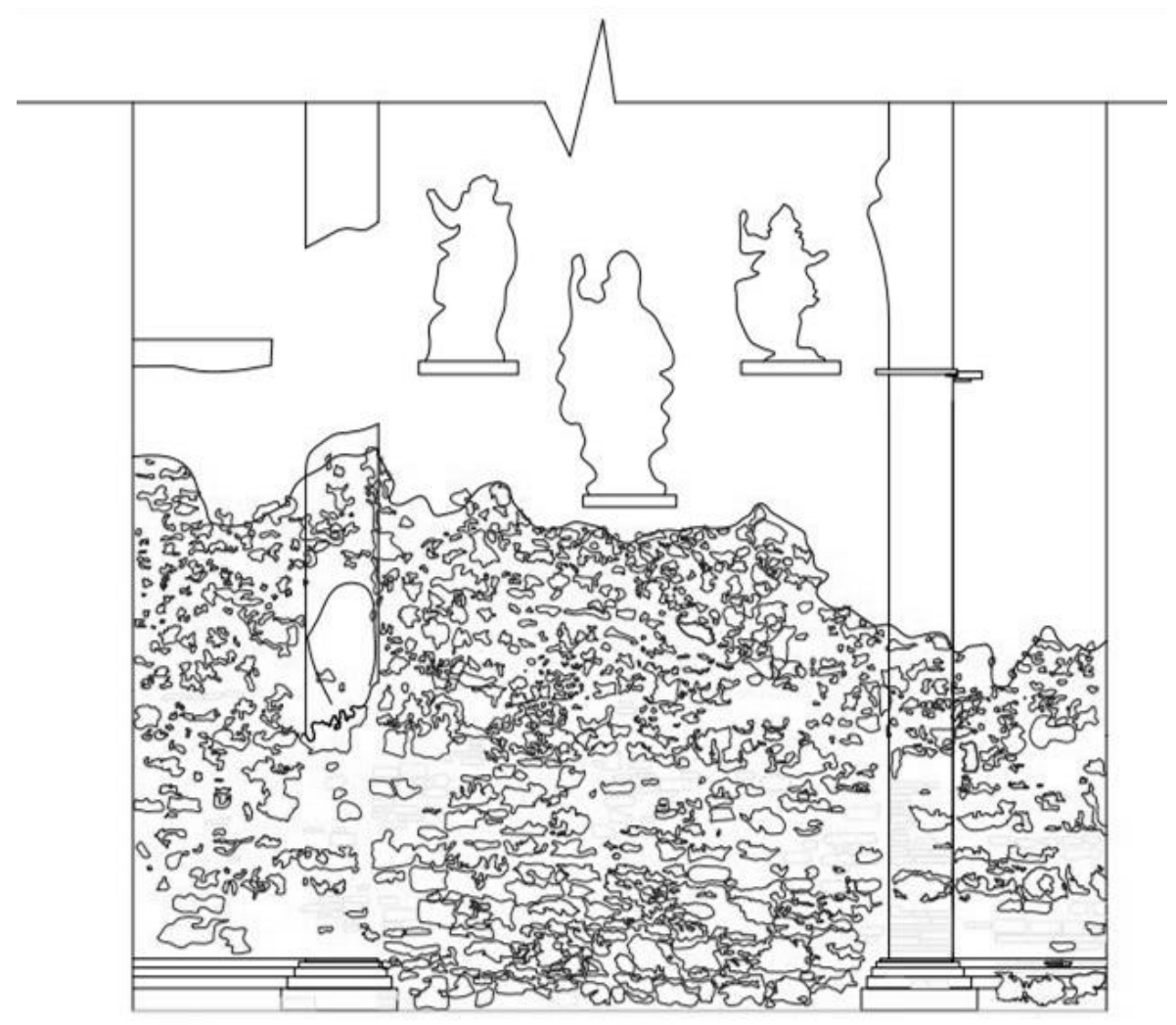

76 Loureiro, A. M. S.; Angélica, R. S.; Sanjad, T. A. B. C.; Oliveira, M. M. de; Costa, M. L. 
Figura 6 - Levantamento de danos da alvenaria do transepto direito da Igreja de Santo Alexandre

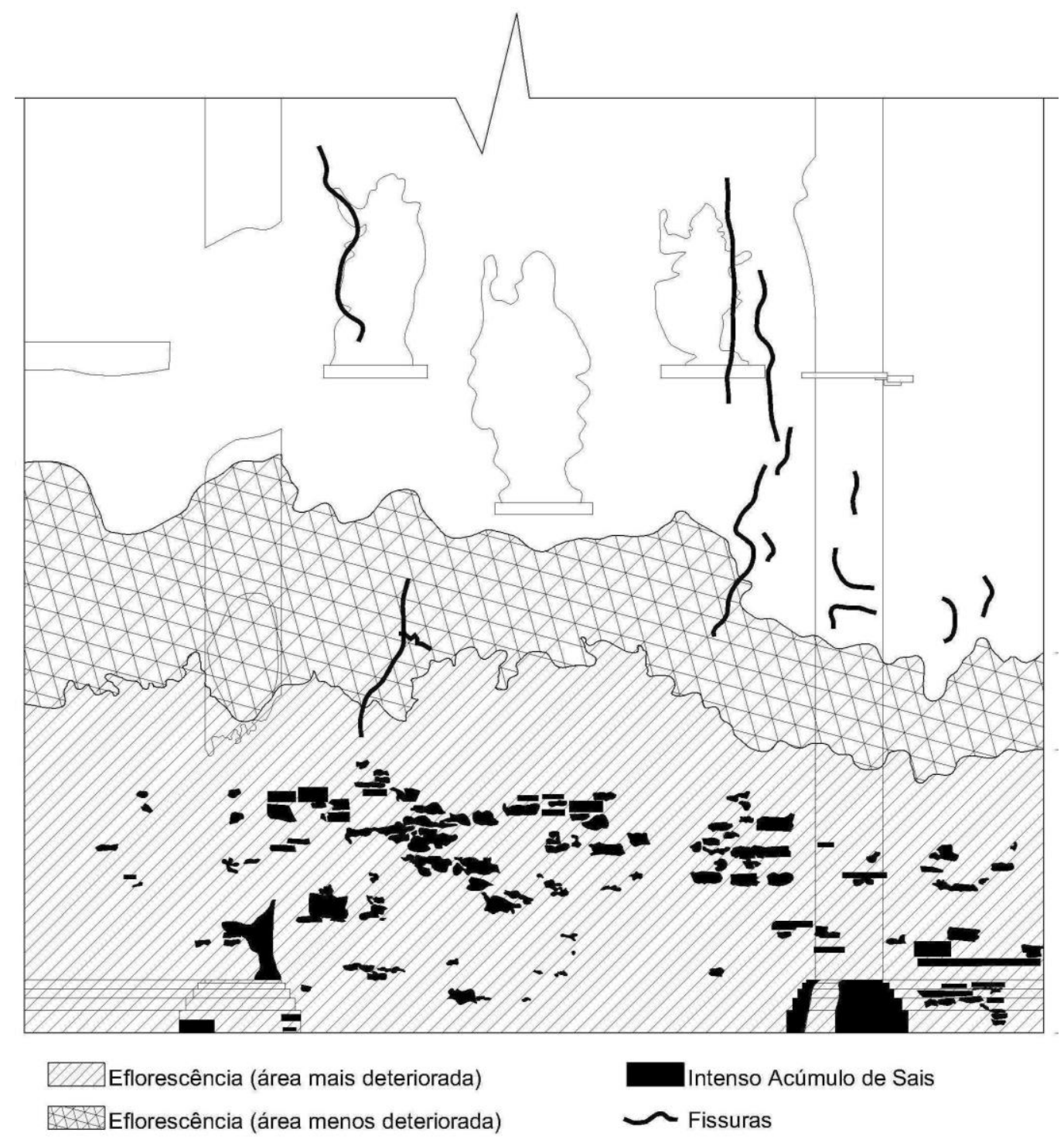

O agregado grosso da argamassa apresentou curva granulométrica característica de areia média (D50 $\sim 350 \mu \mathrm{m}$ ou 45\#), unimodal e com pouca assimetria (Fig. 7a), enquanto o material fino apresentou D50 $16 \mu \mathrm{m}$ (silte fino a médio) (Figura 7b).

A curva granulométrica dos grossos mostra que a areia era o agregado mais utilizado nas argamassas antigas. Essa curva granulométrica se assemelha à faixa da areia de edifícios históricos anteriores ao século XIX citados em estudo sobre argamassas tradicionais de cal do Brasil (SANTIAGO, 2007).
A curva granulométrica dos finos revela a presença de resíduos na mistura, o silte, encontrado em proporção considerada desprezível, como observado na análise de traço. Este e outros resíduos eram comuns em argamassas antigas de cal, pois não havia preocupação com a limpeza dos materiais antes de sua aplicação na construção dos edifícios (KANAN, 2008).

Do ponto de vista mineralógico, a argamassa é constituída de quartzo $\left(\mathrm{SiO}_{2}\right)$, calcita $\left(\mathrm{CaCO}_{3}\right)$, caulinita $\left(\mathrm{Al}_{2} \mathrm{Si}_{2} \mathrm{O}_{5}(\mathrm{OH})_{4}\right)$ e halita $(\mathrm{NaCl})$ (Figura 8). 
Figura 7 - (a) Curva granulométrica dos grossos; e (b) curva granulométrica dos finos da argamassa de assentamento

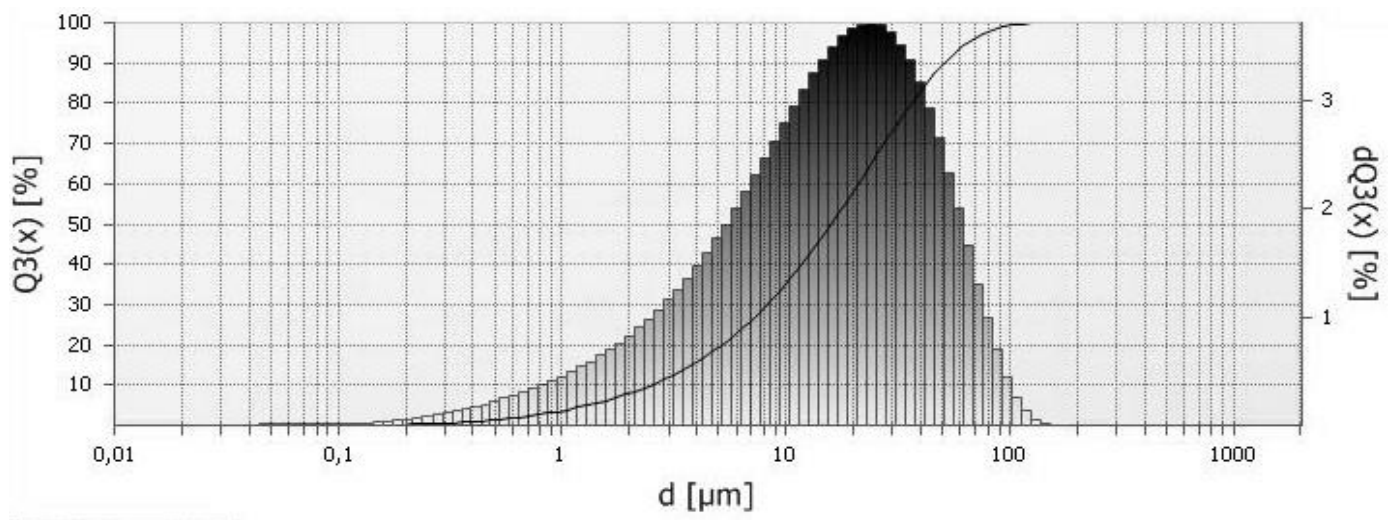

$A^{0 d Q 3}(x)-0 Q 3(x)$

(a)

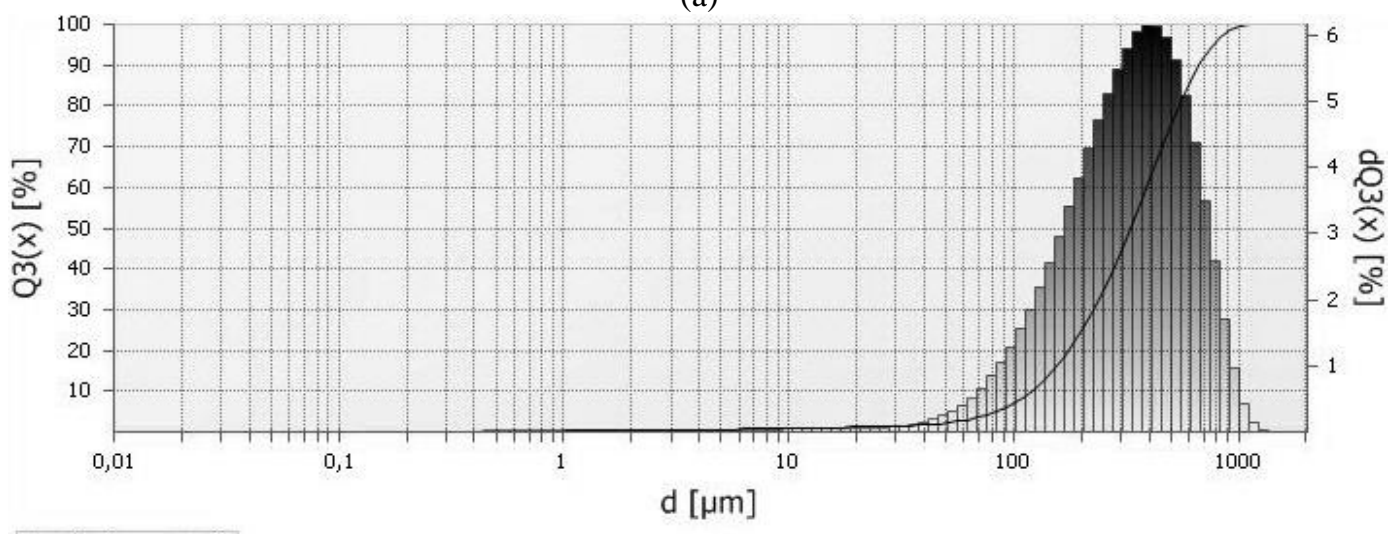

$\mathbb{A}^{0} \mathrm{dQ} 3(x)-0 \mathrm{Q} 3(x)$

(b)

Figura 8 - Difratograma de raios $\mathrm{X}$ mostrando os principais constituintes mineralógicos da argamassa, exemplificada pela amostra 3B: caulinita $(\mathrm{Kln})$, quartzo $(\mathrm{Qtz})$, calcita (Cal) e halita $(\mathrm{HI})$

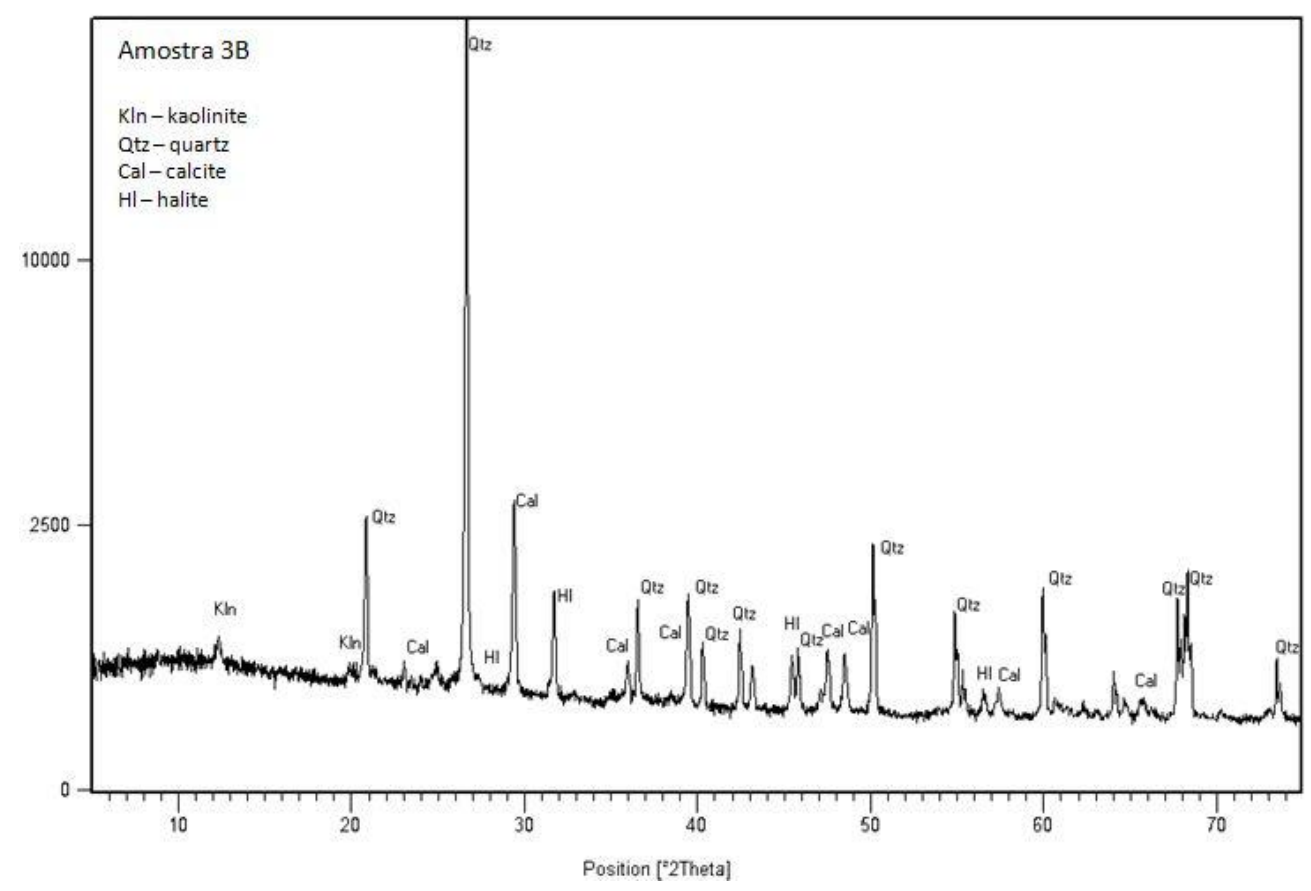

78 Loureiro, A. M. S.; Angélica, R. S.; Sanjad, T. A. B. C.; Oliveira, M. M. de; Costa, M. L. 
A composição mineralógica da alvenaria mostra claramente a natureza de seus principais constituintes: o quartzo proveniente da areia utilizada como agregado; a calcita proveniente da carbonatação da cal utilizada como aglomerante; e a caulinita proveniente do barro, também utilizado como aglomerante em algumas argamassas. A halita sugere a presença de um produto neoformado da eflorescência muito comum em argamassas antigas de cal (LAZZARINI et al., 2007; MOROPOULOU; BAKOLAS; BIBIKOU, 2000).

\section{Umidade}

O teor médio da umidade é de 4,84\% (Figura 9). Observa-se nitidamente que em cada perfil vertical os valores mais elevados encontram-se na base, diminuindo progressivamente para o topo, o que demonstra que há ascensão da água na parede, verticalmente. Assim, é possível classificar a umidade como ascendente.

Adicionalmente, observam-se também variações laterais da esquerda para a direita, havendo acréscimo de um ponto percentual da lateral esquerda para o centro, e um acréscimo de aproximadamente três pontos percentuais da lateral esquerda para a lateral direita.

A umidade ascendente pode ter sido ocasionada pela presença de um jardim descoberto na face externa da alvenaria, inserido no projeto da intervenção de 1998. Assim, a água da chuva penetra no terreno, que, por sua vez, está em contato com a base da alvenaria.

\section{Sais}

Os principais ânions salinos identificados na alvenaria do transepto direito são cloreto, nitrato e sulfato, e suas concentrações variam em relação aos pontos de coleta (Figura 10).

Comparando-se as figuras, observa-se claramente que os cloretos e os nitratos estão em maior quantidade em relação aos sulfatos e possuem distribuição homogênea.

Os sulfatos estão distribuídos de forma heterogênea, com pontos de média e pequena quantidade, além de dois pontos com ausência deste sal.

\section{Teste quantitativo de sais cloreto}

Os resultados da análise quantitativa de cloreto indicam uma distribuição praticamente homogênea em relação aos pontos coletados, representados na Figura 11. O teor médio das nove amostras analisadas é de $0,26 \%$, com variação de $0,22 \%$ a $0,29 \%$. Aparentemente, a porção central da alvenaria apresenta maior concentração em relação às laterais.

Figura 9 - Percentual do teor de umidade em cada ponto de coleta, que caracteriza a umidade presente como ascendente

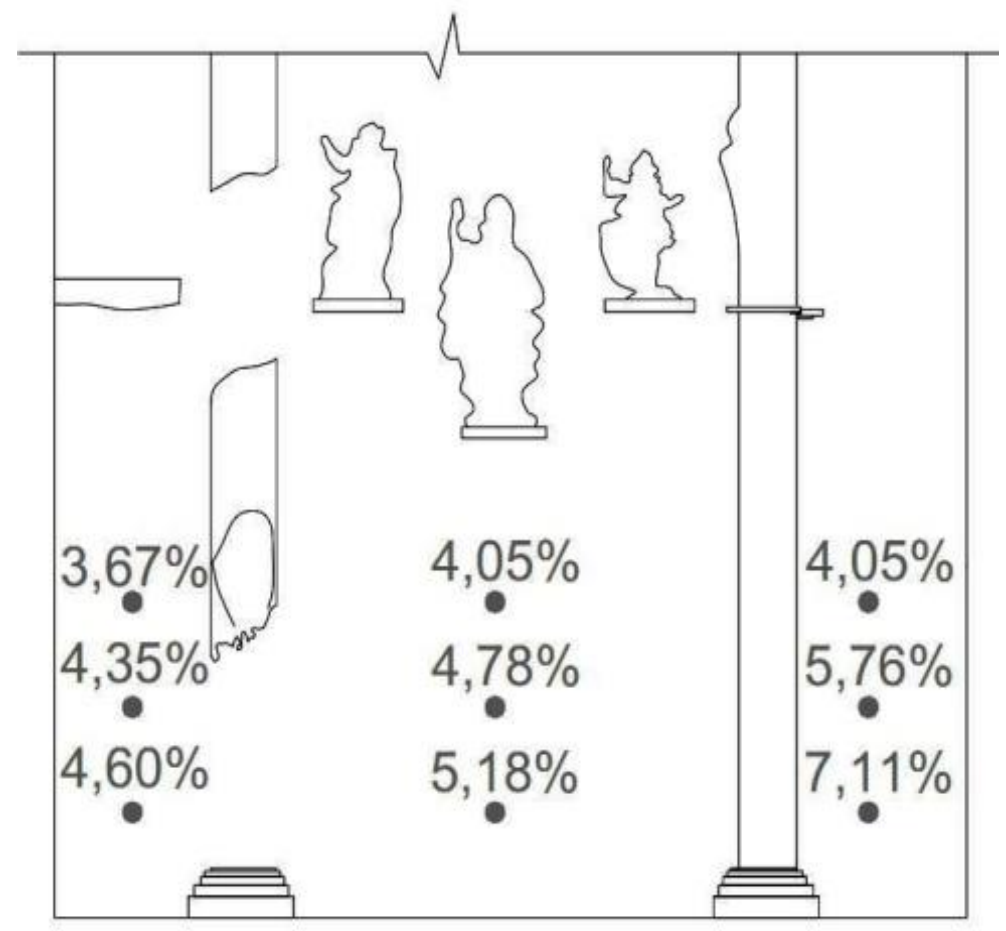


Figura 10 - Teste qualitativo de sais

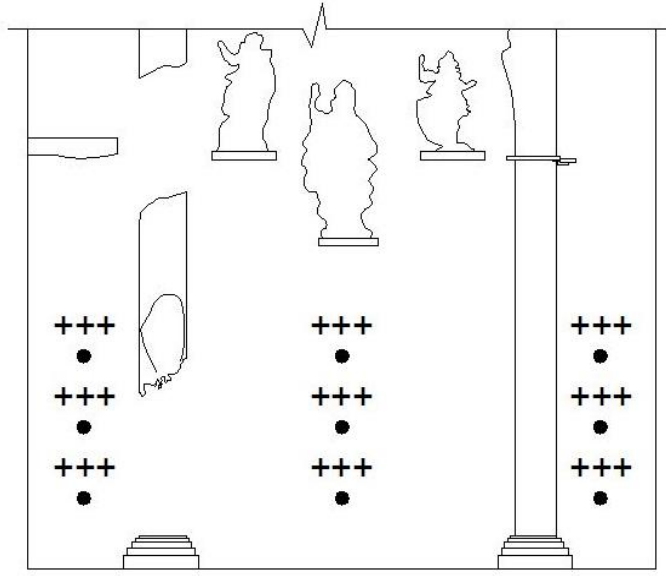

CLORETOS

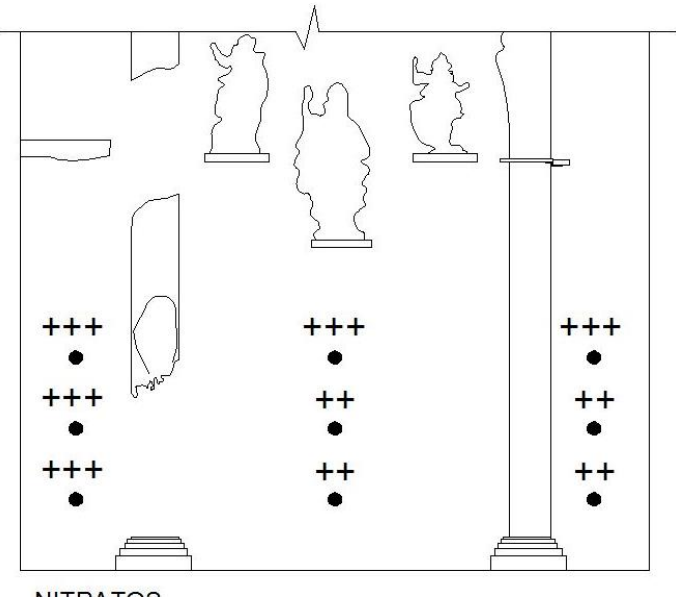

(b) Nitratos

(a) Cloretos

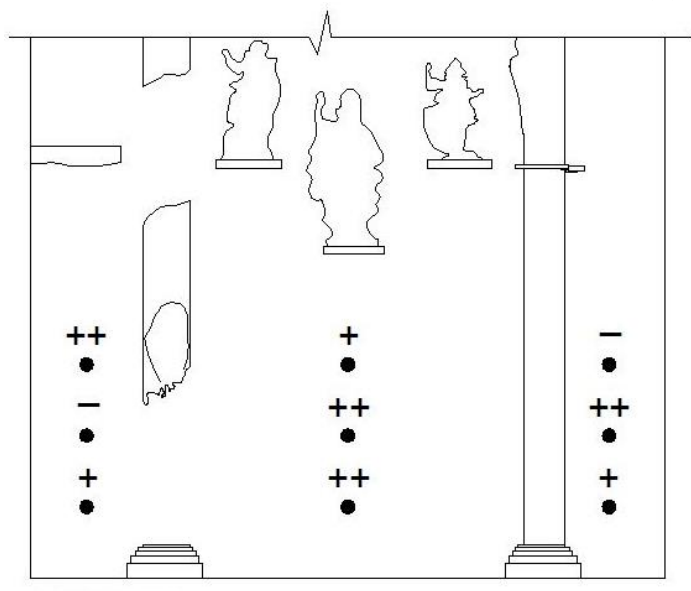

SULFATOS

(c) Sulfatos-

Nota: Legenda:

- Ausência;

+ Pequena quantidade;

++ Média quantidade; e

+++ Grande quantidade.

Figura 11 - Distribuição quantitativa do cloreto na alvenaria do transepto direito

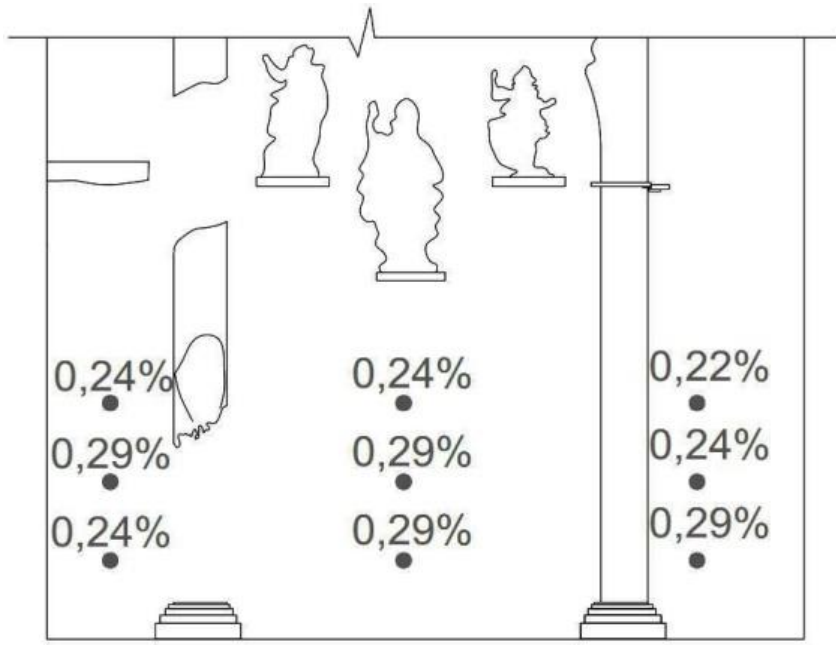

80 Loureiro, A. M. S.; Angélica, R. S.; Sanjad, T. A. B. C.; Oliveira, M. M. de; Costa, M. L. 
Provavelmente a homogeneidade na distribuição do cloreto está relacionada ao fato de ser um sal muito solúvel, sendo, desse modo, facilmente transportado para todas as regiões da alvenaria (BOURGES; VERGES-BELMIN, 2008). Isso foi observado de maneira similar em experimento feito na Igreja de St. George, na Austrália, onde foi verificada uma distribuição idêntica desses sais ao longo da alvenaria analisada (WEBER; GAGGL; SZAMBELAN, 1996).

\section{Discussões}

A degradação atuante na alvenaria é uma consequência da ação da umidade e eflorescência. Esses dois agentes ocasionam destacamento de camadas e pulverização de argamassa (CHAROLA, 2000; HENRIQUES, 1994), mesmo se tratando de uma argamassa forte, conforme constatado na análise de traço. A região mais degradada encontra-se na parte inferior da alvenaria, como seria de se esperar, pelo contato com o solo e falta de impermeabilização, pelas limitações tecnológicas da época.

Como a umidade está sempre presente na base, é possível que ocorram ciclos de precipitação e dissolução dos sais de forma recorrente (CHAROLA, 2000; KANAN, 2008), motivo pelo qual a região encontra-se mais degradada. Esses ciclos podem estar relacionados, por exemplo, a variações climáticas sazonais, como a alternância dia-noite, ou anualmente, com a estação chuvosa e a estação seca.

Verifica-se que na lateral esquerda a degradação alcança uma altura de aproximadamente $3,50 \mathrm{~m}$, enquanto na lateral direita atinge $2,34 \mathrm{~m}$ de altura. Comparando-se esses dados aos teores de umidade, observou-se que os locais mais úmidos estão menos degradados. Isso ocorre possivelmente por conta da solubilidade dos sais, ou seja, onde há menos umidade os sais cristalizam-se mais facilmente e, consequentemente, provocam maiores danos.

Os blocos de arenito ferruginizado podem ter funcionado como barreira para infiltração dos sais, pois seus poros foram preenchidos por goethita. Dessa forma, a cristalização dos sais ter-se-ia iniciado pela argamassa, fator que pode ser visualizado in loco, uma vez que a argamassa encontra-se mais degradada se comparada aos blocos de arenito presentes na estrutura.

A origem de sal na edificação pode ser variada. No caso do cloreto de sódio, pode ser proveniente da contaminação dos materiais utilizados na construção, uma vez que a areia e a cal utilizadas em argamassas antigas eram oriundas de ambiente marinho (CRUZ, 1898; FERREIRA, 1983).

Os sulfatos podem ser provenientes de intervenções recentes e correspondem à reação entre a argamassa de cal existente e a possível aplicação de argamassa de cimento (CHAROLA, 2000), uma vez que em algumas áreas são observados resquícios de cimento, assim como na alvenaria lateral à analisada.

Além disso, há possibilidade da ocorrência de cloretos, nitratos e sulfatos em período posterior à construção através da umidade ascendente, que carreia sais existentes no solo para os materiais da edificação (HENRIQUES, 1994):

(a) os cloretos podem ser oriundos de um depósito de sal situado próximo à edificação;

(b) os sulfatos podem ser provenientes de construções contemporâneas próximas à edificação; e

(c) os nitratos podem ser provenientes de material orgânico encontrado no solo por conta de tubulações de esgoto danificadas próximas à edificação ou de excrementos nas alvenarias da edificação (urina).

O trânsito de veículos de grande porte e a possível acomodação do solo podem ter auxiliado no surgimento de fissuras na alvenaria, que propiciaram ainda mais a ascensão de águas salinas. Essas problemáticas, juntamente com a eflorescência e a presença de umidade, podem favorecer a degradação de regiões mais internas, uma vez que o substrato se torna mais exposto à degradação.

\section{Conclusões}

A remoção do reboco e a climatização foram cruciais para acelerar a degradação da alvenaria, pois tais intervenções alteram as condições microclimáticas preestabelecidas, acelerando o processo de eflorescência, que é favorecido pela ação de umidade ascendente.

A umidade ascendente provavelmente está relacionada à presença de um jardim nas adjacências da alvenaria, implicando também o transporte dos sais do solo para a estrutura, o que justifica a procedência de nitratos, que são sais geralmente provenientes de matéria orgânica presente no solo.

No interior da alvenaria, os sais são transportados em forma de íons para a superfície do substrato, e nesse momento a água tende a evaporar. Quando a água evapora, os íons precipitam-se na superfície do substrato formando minerais que ocasionam 
pressões nos poros do material e, consequentemente, provocam a degradação: destacamento de camadas e pulverização de argamassa (CHAROLA, 2000; HENRIQUES, 1994).

As alternativas sugeridas para caracterização e mapeamento se mostraram eficientes e auxiliaram no diagnóstico correto da problemática existente, norteando quais tipos de intervenções devem ser feitas para amenizar a degradação da alvenaria.

Os resultados desta pesquisa representam um passo importante para a conservação e a restauração de alvenarias mistas degradadas por eflorescência salina em edifícios históricos, pois fornecem subsídios para diagnóstico, caracterização e mapeamento do problema, auxiliando na conservação dessas alvenarias e evitando perda ou descaracterização do patrimônio histórico edificado.

\section{Referências}

BOURGES, A.; VERGES-BELMIN, V.

Comparison and Optimization of Five Desalination System on the Inner Walls of Saint Philibert Church in Dijon, France. In: SALT WEATHERING ON BUILDINGS AND STONE SCULPTURES, 1., Copenhagen, 2008. Anais... Copenhagen: University of Cyprus, 2008.

CHAROLA, E. Salts in the Deterioration of Porous Materials: an overview. Journal of the American Institute for Conservation, v. 39, n.3, p. 327-343, 2000.

CRUZ, E. História de Belém. Belém:

Universidade Federal do Pará, 1898.

FERREIRA, A. R. Viagem Filosófica ao Rio Negro. Belém: Museu Paraense Emílio Goeldi, 1983.

HENRIQUES, F. M. A. Humidade em Paredes. Lisboa: LNEC, 1994.
KANAN, M. I. Manual de Conservação e Intervenção em Argamassas e Revestimentos à Base de Cal. Brasília: IPHAN; Programa Monumenta, 2008.

LAZZARINI, L. et al. Insight Into the Conservation Problems of the Stone Building "Bab Agnaou", a XII cent. monumental gate in Marrakech (Morocco). Journal of Cultural Heritage, Morocco, v. 8, p. 315-322, 2007.

MOROPOULOU, A.; BAKOLAS, A.; BIBIKOU, $\mathrm{K}$. Investigation of the Technology of Historic Mortars. Journal of Cultural Heritage, v. 1, n. 1, p. 45-58, 2000.

PARÁ. Secretaria Executiva de Cultura do Estado. Feliz Lusitânia: Museu de Arte Sacra. Belém: SECULT, 2005.

SANTIAGO, C. C. Argamassas Tradicionais de Cal. Salvador: EDUFBA, 2007.

WEBER, J.; GAGGL, W. H. L.; SZAMBELAN, R. Origin, Mechanisms and Effects of Salts on Degradation of Monuments in Marine and Continental Environments. Bari: Zezza, 1996.

\section{Agradecimentos}

À Fapespa, pela bolsa de mestrado concedida.

À Secult, que gentilmente autorizou a realização desta pesquisa.

Aos laboratórios da UFPA e da UFBA, que possibilitaram a realização das análises laboratoriais: Laboratório de Conservação, Restauração e Reabilitação (LACORE/UFPA), Laboratório de Caracterização Mineral (LCM/UFPA), Laboratório de Mineralogia e Geoquímica Aplicada (LaMIGA/UFPA) e Núcleo de Tecnologia da Preservação e da Restauração (NTPR/UFBA). 


\section{Alexandre Máximo Silva Loureiro}

Laboratório de Conservação, Restauração e Reabilitação, Instituto de Tecnologia | Universidade Federal do Pará | Av. Augusto Corrêa, 1, Guamá | Belém - PA - Brasil | CEP 66075-110 | Tel.: (091) 99123-1248 | E-mail: alexandre_loureiro1@hotmail.com

\section{Rômulo Simões Angélica}

Laboratório de Caracterização Mineral, Instituto de Geociências | Universidade Federal do Pará | Tel.: (091) 3201-8007 | E-mail: angelica@ufpa.br

\section{Thais Alessandra Bastos Caminha Sanjad}

Laboratório de Conservação, Restauração e Reabilitação, Instituto de Tecnologia | Universidade Federal do Pará | Tel.: (091) 3201-8721 E-mail: thais@ufpa.br

\section{Mário Mendonça de Oliveira}

Núcleo de Tecnologia da Preservação e da Restauração, Escola Politécnica | Universidade Federal da Bahia | Rua Prof. Aristides Novis, 2, Federação | Salvador - BA - Brasil | CEP 40210-630 | Tel.: (071) 3283-9858 | E-mail: mmo1936@gmail.com

Marcondes Lima da Costa

Laboratório de Mineralogia e Geoquímica Aplicada, Instituto de Geociências | Universidade Federal do Pará | Tel.: (091) 3249-5028

E-mail: mlc@ufpa.br

\section{Revista Ambiente Construído}

Associação Nacional de Tecnologia do Ambiente Construído

Av. Osvaldo Aranha, $99-3^{\circ}$ andar, Centro

Porto Alegre - RS - Brasil

CEP $90035-190$

Telefone: +55 (51) 3308-4084

Fax: +55 (51) 3308-4054

www.seer.ufrgs.br/ambienteconstruido

E-mail: ambienteconstruido@ufrgs.br 